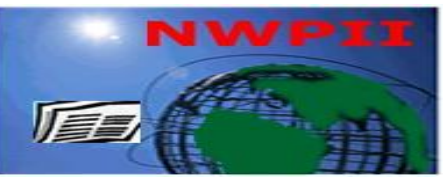

American Journal of Biomedical Sciences

ISSN: 1937-9080

nwpii.com/ajbms

\title{
Therapeutic Role of Surfactant during Mitochondrial Membrane Mediated Apoptosis in Endotoxin Induced Acute Respiratory Distress Syndrome
}

\author{
Neha Mittal and Sankar Nath Sanyal*
}

Department of Biophysics, Panjab University, Chandigarh-160014, India

"Corresponding author:

Dr. S. N. Sanyal

Department of Biophysics

Panjab University

Chandigarh-160014

India

Phone: +91-0172-2534122

Email: $\quad \underline{\text { sanyalpu@gmail.com or sanyal@pu.ac.in }}$

Received: 2 April 2011; | Revised: 5 September 2011; | Accepted: 14 November 2011

\begin{abstract}
Acute respiratory distress syndrome (ARDS) induced by lipopolysaccharide (LPS) is known to be associated with pulmonary cytokine production resulting in infiltration of neutrophils and pulmonary injury. The study presented here is focused on the changes in cell death regulating proteins during lung injury and studied the relationship between the LPS challenged ARDS and the subsequent role of surfactant therapy against ARDS. Apoptotic features, such as induction of DNA fragmentation ladders in lung tissue, expression of cytoplasmic proteins (Bcl-2, Bax), mitochondrial proteins (cytochrome c, Apaf-1) and activation of caspases were detected following LPS exposure. Instillation of the surfactant derived from the natural source as well as synthetic surfactant prevents LPS induced apoptosis. These results suggest that the mechanism of induction of apoptosis by LPS depends on mitochondrial dysfunction and the anti-apoptotic effects of surfactant treatment conferred protection in the rat model during lung injury mediated via suppression of mitochondrial intrinsic pathway.
\end{abstract}

Keywords: Apaf-1, ARDS, Bax, Bcl-2, Caspase, Cytochrome-c, LPS, Surfactant.

\section{Introduction}

Acute lung injury (ALI), which manifests itself clinically as acute respiratory distress syndrome (ARDS), is defined as a 'syndrome of acute pulmonary inflammation and increased capillary endothelial permeability' and can occur in response to both direct (aspiration, pneumonia, toxic inhalation) and systemic (sepsis, shock, cardiopulmonary bypass) challenge [1]. ARDS is associated with a neutrophil-mediated inflammatory response that causes alveolar epithelium/endothelium breakdown, increased vascular permeability and edema [2]. In addition to neutrophil apoptosis and enhanced 
endothelial/epithelial cell apoptosis, abnormal surfactant function has also been implicated in the pathogenesis of ARDS [3,4]. Several hypotheses have been proposed to account for the functional changes that occur in ARDS surfactant [5] demonstrating decreased phospholipid and apoprotein contents in lung lavage samples from both patients with ARDS [4] and animal models [6]. Studies in critically ill patients have also shown that ARDS is associated with increased cell death [7], whereas investigation of the effect of apoptosis inhibitors showed remarkable increases in survival using in vivo models of ARDS [8]. The mechanisms responsible for increased apoptosis in ARDS are poorly understood, although roles for Fas/FasL (extrinsic apoptosis), stress (intrinsic apoptosis) and nitric oxide (NO) have been proposed [9].

Apoptosis (programmed cell death) is important for cellular homeostasis in a variety of tissues and may result from multiple insults and occurs along distinct pathways leading either to apoptosis or to necrosis [10]. The mechanisms regulating apoptosis are complex and involve the interaction of nuclear and cytoplasmic proteins. Cells undergo apoptosis through distinct pathways that can be subdivided according to the initiating caspases, a family of proteases that are important in regulating apoptosis [11]. The first pathway (the receptor-mediated extrinsic pathway) is activated by members of the tumor necrosis factor family, such as Fas ligand (FasL) binding to its receptor (Fas), which results in activation of caspase-8. The second pathway (the mitochondrial intrinsic pathway) is activated in response to chemical and physical stress, which triggers the cytoplasmic release of pro-apoptotic mitochondrial proteins leading to activation of caspase-9 [12].

The regulation of mitochondrial membrane integrity is an important process regulating apoptosis. Pro-apoptotic Bcl-2 homologues Bid, $\mathrm{Bax}, \mathrm{Bad}$ and Bak are able to localize to the outer mitochondrial membrane where they alter its permeability. Classically, cytochrome $c$ is released from the inter membrane space into the cytoplasm where it forms a complex with Apaf-1 (apoptosis protease activating factor-1) and caspase 9, together termed the apoptosome which subsequently processes the executioner caspase-3
[13] and other molecular changes such as loss of plasma membrane symmetry and exposure of phosphatidylserine [14]. Permeability changes induced by Bcl-2 family members may permit the release of the mitochondrial ROS into the cytoplasm [15] where they are able to promote alternative cell death pathways [16].

We have shown here that the LPS triggers the release of cytochrome c from mitochondria which binds to Apaf-1, and promotes the activation of caspase-9. This further activates the effector caspase- 3 and mediates the cleavage of apoptotic regulators, resulting in morphological features of apoptosis in an LPS-induced acute lung injury model. Administration of surfactant in vivo inhibited the caspase-3 activity and therefore, prevented the mitochondrial pathway of caspasemediated apoptosis triggered by LPS or by a variety of stimuli, such as inflammatory cytokines, growth factors, reactive oxygen, and others, which are also involved in this model.

\section{Materials and Methods}

\subsection{Animal modal}

Male rats of S.D. strain, weighing $150-200 \mathrm{~g}$ were taken from the Central Animal House of Panjab University and kept in polypropylene cages and supplied with pellet diet and drinking water $a d$ libitum. Control animals were administered with $500 \mu \mathrm{l}$ of the buffer $(50 \mathrm{mM}$ Tris- $\mathrm{HCl}, \mathrm{pH}-7.4$, $150 \mathrm{mM} \mathrm{NaCl}, 1 \mathrm{mM} \mathrm{NaN}_{3} \& 0.2 \mathrm{mM}$ PMSF). For

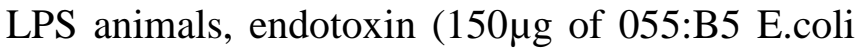
LPS) was suspended in $500 \mu 1$ of surfactant buffer and intratracheal instillation procedure was followed as described earlier for $72 \mathrm{hrs}$ [17]. Two hours prior to killing, surfactant isolated from porcine $(0.5 \mathrm{mg}$ protein $+4.6 \mathrm{mg} \mathrm{lipid} / 500 \mu \mathrm{l})$ or

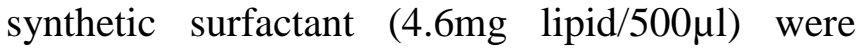
intratracheally instilled in P-SF and S-SF groups respectively, after LPS administration following the identical instillation procedure. The animals were sacrificed at 72 hours after buffer or LPS instillation. All of the animal procedures as reported here had been carried out following the guidelines approved by the Panjab University Ethical Committee on the use of the experimental animals for biomedical research. 


\subsection{Surfactant preparation}

Surfactant was isolated from porcine lung homogenate (P-SF) by sucrose density gradient method [18] and protein free synthetic surfactant (S-SF) was prepared with dipalmitoylphosphohatidyl choline (DPPC), hexadecanol and tylaxopol [18].

\subsection{Western blot Analysis}

Lung protein samples $(50 \mu \mathrm{g})$ from each treatment group were separated on 10\% SDSPAGE. The separated proteins were electrophoretically transferred to the nitrocellulose membrane (Genei, Bangalore, India) and the transfer was checked through the staining with Ponceau S. Immunoblot was prepared using primary antibodies $\left(\mathrm{Bcl}_{2}, \mathrm{Bax}\right.$, Cytochrome-c, Apaf-1, Caspase-3, 9 and $\beta$-actin-1:1000) from Santa Cruz Biotechnology Inc., (CA, USA) and alkaline phosphatase-conjugated respective secondary antibodies at a dilution of 1:10,000 (Genei, Bangalore, India). BCIP-NBT detection system was used to develop the blot. Bands obtained were densitometrically analyzed using Image $\mathbf{J}$ software and the density expressed as gray values in densitometric units. For preparation of mitochondrial and cytosolic fractions, lungs were removed from the different treatment groups and lysates were prepared in fresh ice-cold protein lysis buffer $(10 \mathrm{mM}$ Tris, $100 \mathrm{mM} \mathrm{NaCl}, 5 \mathrm{mM}$ EDTA, $1 \%$ Triton-X100, 1mM PMSF and 2mM DTT [pH-8]). The extracts were cleared of nuclei and residual mucosa by centrifugation at $750 \mathrm{~g}$ for $5 \min \left(4^{\circ} \mathrm{C}\right)$. The mitochondrial fraction was harvested by centrifugation at $10,000 \mathrm{~g}$ for $15 \mathrm{~min}$ at $4{ }^{\circ} \mathrm{C}$ and the supernatant was collected as the cytosolic fraction. For preparation of protein extracts, lungs were removed from the different treatment groups and lysates were prepared in fresh ice-cold protein lysis buffer $[10 \mathrm{mM}$ Tris, $100 \mathrm{mM} \mathrm{NaCl}, 5 \mathrm{mM}$ EDTA, $1 \%$ Triton-X100, 1 $\mathrm{mM}$ PMSF and $2 \mathrm{mM}$ DTT (pH 8)]. The extracts were cleared by centrifugation at $10,000 \mathrm{x}$ g for 10 minutes at $4^{\circ} \mathrm{C}$. The supernatants were collected as the total lysate. Protein concentration was determined by the method of Bradford [19].

\subsection{Immunohistochemical localization studies}

$5 \mu \mathrm{m}$ thick paraffin sections of rat lungs were deparaffinized in two changes of xylene for 10 min each. The sections were then gradually hydrated and brought to water. The non specific staining was blocked by incubating the sections with 2\% BSA in phosphate buffer saline (PBS $10 \mathrm{mM}, \mathrm{pH}$ 7.2). The sections were then incubated with polyclonal antibodies against $\mathrm{Bcl}_{2}, \mathrm{Bax}$, and Cytochrome $\mathrm{c}-1: 1000$ in a moist chamber for $2 \mathrm{hr}$ at $37^{\circ} \mathrm{C}$. After incubation, the sections were washed in PBS, PBS tween (PBS with $0.05 \%$ tween-20) and PBS, successively for 5 min each. The sections were then incubated with respective alkaline phosphatase-labeled secondary antibodies $(1: 10,000)$ for $2 \mathrm{hr}$. Sections were washed again in the same manner as described above and the reaction product was developed using BCIP-NBT. Reaction was terminated by washing with distilled water after which sections were counterstained with eosin and mounted in DPX.

\subsection{Immunofluorescence studies}

$5 \mu \mathrm{m}$ thick paraffin sections of rat lungs were deparaffinized in three changes of xylene for 5 min each. The sections were then gradually hydrated in $100 \%$ and $95 \%$ ethanol for $10 \mathrm{~min}$ each and washed in demonized water for $1 \mathrm{~min}$ with stirring. Slides were then placed in a container, covered with glycine- $\mathrm{HCl}$ buffer, $\mathrm{pH}-$ 3.5 with $0.01 \%(\mathrm{w} / \mathrm{v})$ EDTA and heated for 10 min at $95^{\circ} \mathrm{C}$ with continuous topping off with fresh buffer. The non specific staining was blocked by incubating the sections with 10\% BSA in phosphate buffer saline (PBS, pH 7.2). The sections were then incubated with polyclonal antibody against Apaf-1, Caspase-3 and 9 - 1:1000 in PBS with $1.5 \%$ BSA in a moist chamber for $1 \mathrm{hr}$ at $37^{\circ} \mathrm{C}$. After incubation, the sections were washed three times in PBS successively for 5 min each. The sections were then incubated with FITC conjugated secondary antibody $(1: 10,000)$ in PBS with $1.5 \%-3 \%$ BSA in a moist dark chamber for $1 \mathrm{hr}$ at $37^{\circ} \mathrm{C}$. Sections were washed again in the same manner as described above and were counterstained with DAPI for 20 mins at $37^{\circ} \mathrm{C}$ followed by washing in the PBS as mentioned above. Sections were covered with the coverslips after mounted with the aqueous mounting medium (glycerol: PBS, 1:9) and sealed with the transparent nail polish. 


\subsection{DNA Extraction and Analysis of DNA Fragmentation by Gel Electrophoresis}

Lung tissues were homogenized and the pellet suspended in lysis buffer $(50 \mathrm{mM}$ Tris- $\mathrm{HCl}, \mathrm{pH} 8$, $20 \mathrm{mM}$ EDTA, $\mathrm{pH}$ 8; 1\% SDS; $0.1 \mathrm{mg} / \mathrm{ml}$ proteinase $\mathrm{K})$. The samples were incubated for 2 hrs at $37^{\circ} \mathrm{C}$ with constant shaking. DNA was extracted with 1:1 mixture of phenol:chloroform. After centrifugation for $5 \mathrm{~min}$ at $12,000 \mathrm{~g}$, the aqueous layer was collected and supplemented with one-tenth volume of $6 \mathrm{M}$ sodium acetate, $\mathrm{pH}$ 5.2 and 1 volume of 2-propanol. Samples were stored at $-20^{\circ} \mathrm{C}$ overnight. The precipitated DNA was collected by centrifugation, washed with $70 \%$ ethanol and dissolved in $20 \mu 1$ of Tris-EDTA buffer. The concentration of DNA was estimated by the measurement of optical density at $260 \mathrm{~nm}$. Samples containing $5 \mu \mathrm{g}$ of DNA were then loaded to $1.5 \%$ agarose gels. DNA ladder of $100 \mathrm{bp}$ was used as the standard. Electrophoresis was carried out in TAE buffer (40 mM Tris-acetate, $1 \mathrm{mM}$ EDTA) and DNA was stained with ethidium bromide and photographed with Gel Documentation.

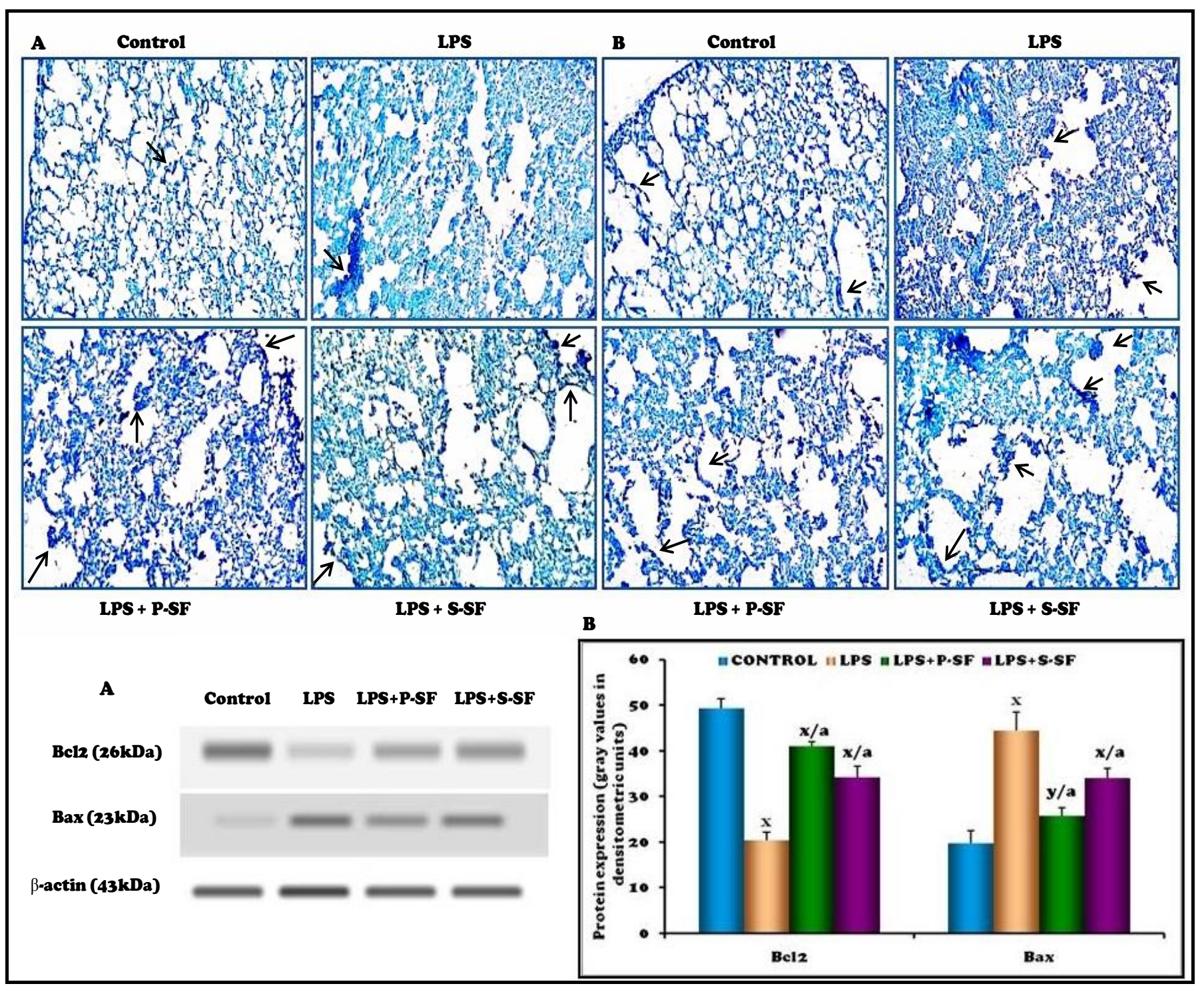

Figure 1- Photomicrographs showing the immunohistochemical localization of Bcl-2 (A) and Bax (B) in paraffin sections. Both proteins were found to be present primarily in the epithelial cells in the control group whereas in all the treated groups expression in alveolar macrophages was also seen along with the epithelial cells. Protein expression of Bcl-2 and Bax in mitochondrial fraction (C) and their densitometric analysis (D) in all the treatments. BCIP/NBT gave dark purple color whereas counterstain methyl green stained the sections light green or cyan (X100). The values are Mean \pm S.D. of 4 animals. ${ }^{\mathrm{x}} \mathrm{p}<0.001,{ }^{\mathrm{y}} \mathrm{p}<0.01$ vs control; ${ }^{\mathrm{a}} \mathrm{p}<0.001$, vs LPS by one way ANOVA. 


\subsection{Statistical analysis}

Statistical analysis was performed using SPSS version 10.0 software. One way analysis of variance (ANOVA) was done to compare the means between the different treatments using Post-Hoc comparison by Least Significant Difference (LSD) method. A value of $p<0.05$ or less (0.01 and 0.001) was considered significant in the present study.

\section{Results}

\subsection{Bcl-2 and Bax expression}

The pro-apoptotic Bax protein plays a major role in the mitochondrion form of apoptosis. Further, mitochondria-mediated cell death also involves down-modulation of Bax-antagonists such as Bcl-2. In the present study, expression of these proteins was studied with immunohistochemistry and Western blot to detect mitochondria-mediated apoptosis. LPS treatment for $72 \mathrm{hrs}$ markedly reduced the expression of Bcl2 , whereas the expression of Bax was seen to be elevated, pointing towards the induction of apoptosis as an important event in the ARDS (Figure 1C). Surfactant co-administration with LPS was successful in renewing apoptosis by increasing the expression of anti-apoptotic Bcl-2 and dropping the expression of pro-apoptotic Bax protein. Results from Western blot for both the proteins were in agreement with the immunohistochemistry outcome. Immunohistochemical localization of both Bcl-2 (Figure 1A and Bax (Figure 1B) was found primarily in the epithelial cells in the control group whereas in all the treated groups expression in alveolar macrophages were also seen along with the epithelial cells.

\subsection{Cytochrome c release and Apaf-1 expression}

We studied cytochrome $c$ release into the cytosol as an independent evaluation of alterations of mitochondrial membrane permeability in the present study. In cytosolic fraction from LPS treated rats, a significant expression of cytochrome $c$ was observed, signifying a redistribution of cytochrome $c$ from mitochondria to the cytosolic fraction (Figure 2C). By contrast, in all the other groups, a lower expression of cytochrome $c$ suggests that cytochrome $c$ was primarily sequestered in the mitochondria. Results from immunohistochemical analysis were in agreement with the results from Western blot (Figure 2A). Tissue sections from LPS treated group showed strong expression of cytochrome $c$ as compared to all the other groups, in which prominent expression was seen, both in epithelial as well as alveolar macrophages.

Apaf-1 is the molecular core of the apoptosome, a multiproteic complex mediating the so-called mitochondrial (intrinsic) pathway of cell death, its expression was seen by immunofluorescence in the present study. Secondary antibody labeled with FITC fluoresces with Apaf-1 expression, detected with anti-Apaf-1 antibody counterstained by DAPI. LPS treatment for $72 \mathrm{hrs}$ led to a significant increase in the expression of Apaf-1 in the lung tissue (Figure 2B). Low expression was seen in control group, whereas surfactant was also able to suppress the enhanced level of Apaf-1 when administered simultaneously with LPS. Results from Western blot were found to be in agreement with the immunofluorescence outcome.

\subsection{Caspase-9 \& 3 involved in regulation of apoptosis}

In the present study, we studied the expression of caspase-9 and caspase-3 (Figure 3A $\&$ 3B) by immunofluorescence and by Western blot (Figure 3D) to evidence LPS-induced apoptosis. The expressions were found to be increased significantly after LPS treatment in rat lung as compared to control and LPS+SF groups. As caspase-9 is involved in the activation of the caspase cascade responsible for apoptosis execution and in turn, cleaves and activates the effector caspases, its increased expression may be responsible for enhanced protein expression of caspase- 3 . The lung tissue from LPS + SF treated groups showed the restored levels of both the caspases as seen by both immunofluorescence and by Western blot.

\subsection{DNA fragmentation}

Breakdown of nuclear DNA into its nucleosomal fragments is a key feature of the 
programmed cell death or apoptosis. Fragments of DNA from lung tissue were extracted by phenol:chloroform method and analyzed on agarose gel electrophoresis from each group. LPS treatment contributes to increase DNA laddering seen in Figure 4 whereas decrease in DNA laddering is seen in lungs given surfactant along with LPS. No fragments were seen in the control group.

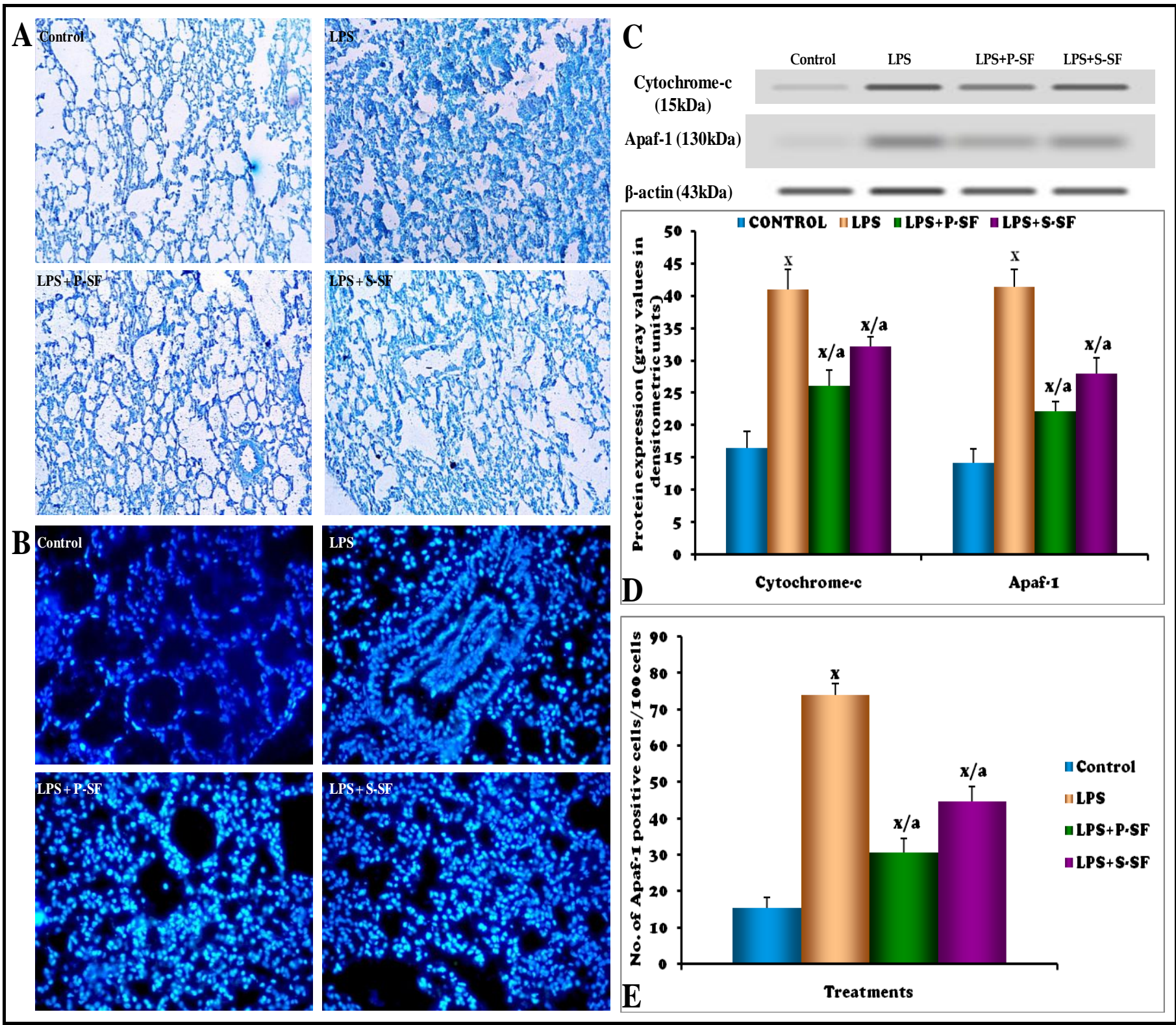

Figure 2- Photomicrographs showing the immunohistochemical localization of cytochrome $\mathrm{c}$ in paraffin sections (A) and localization of Apaf-1 by immunofluorescence (B) Tissue sections from LPS treated group showed strong expression of cytochrome $c$ and Apaf-1 as compared to all the other groups, in which prominent expression was seen, both in epithelial as well as alveolar macrophages. Protein expression of cytochrome $\mathrm{C}$ and Apaf-1 in all the treatment groups (C) and its densitometric analysis (D). BCIP/NBT gave dark purple color whereas counterstain methyl green stained the sections light green or cyan in cytochrome c (X100) whereas FITC conjugated secondary antibody was used and counterstained with the DAPI in case of Apaf-1 (X400). (E) Quantitative analysis of the Apaf-1 positive cells in all the treatments. 100 cells were counted in each four different slides from each group and percent of positive cells calculated. The values are Mean \pm S.D. of 4 animals. ${ }^{\mathrm{x}} \mathrm{p}<0.001$ vs control; ${ }^{\mathrm{a}} \mathrm{p}<0.001$, vs LPS by one way ANOVA. 


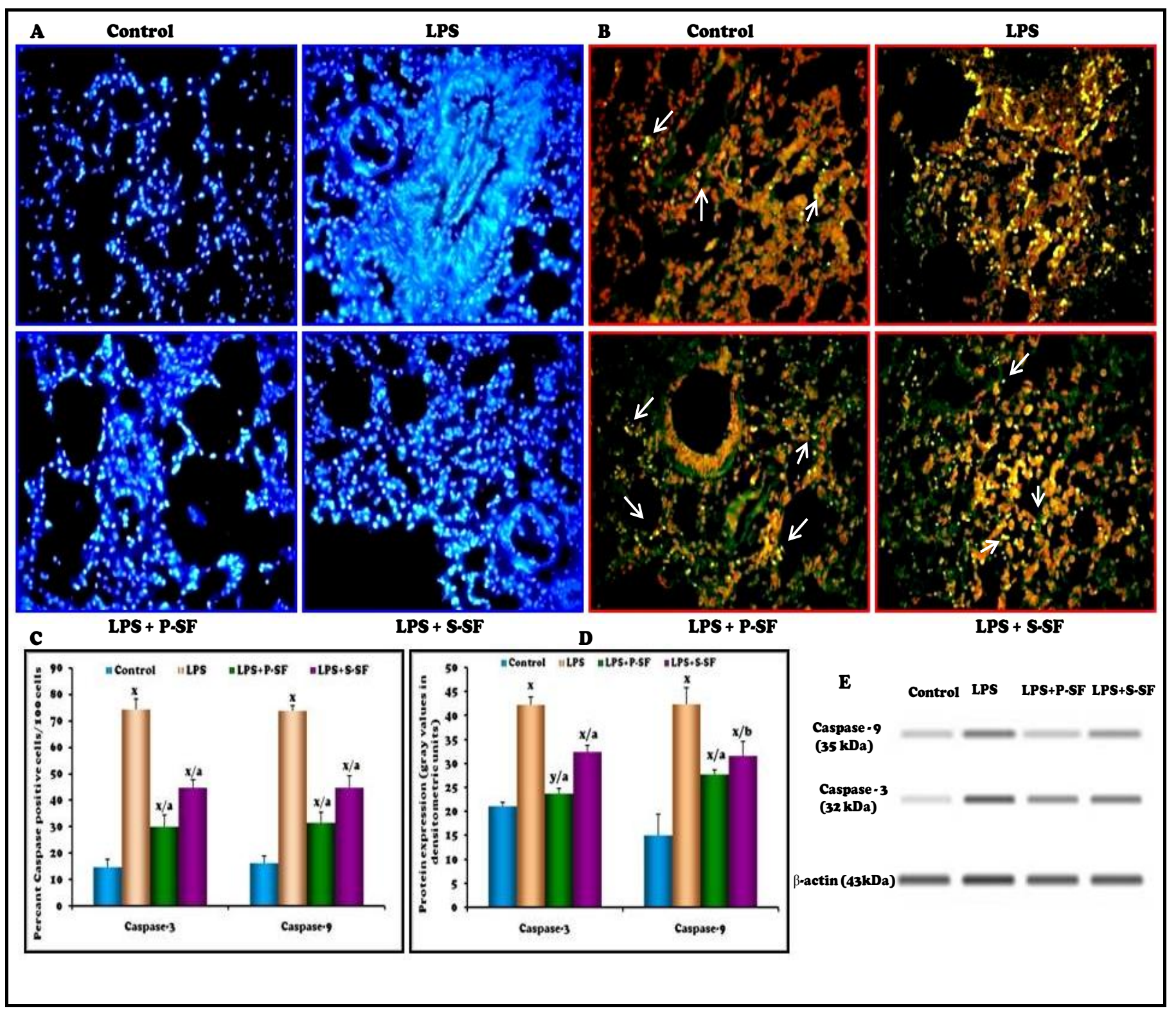

Figure 3- Photomicrographs showing the localization (arrows) of caspase 9 (A) and 3 (B) in paraffin sections by immunofluorescence (X400). FITC conjugated secondary antibody was used while DAPI and PI were used as counterstains in caspase 9 and caspase 3, respectively. The expression was increased significantly after LPS treatment in rat lung as compared to control and LPS+SF groups. (C) Quantitative analysis of the caspase positive cells in all the treatments. 100 cells were counted in each four different slides from each group and percent of positive cells calculated. Protein expression of caspase 9 and 3 by Western blot in all the treatment groups (D) and its densitometric analysis (E). The values are Mean \pm S.D. of 4 animals. ${ }^{\mathrm{x}} \mathrm{p}<0.001,{ }^{\mathrm{y}} \mathrm{p}<0.01$ vs control; ${ }^{\mathrm{a}} \mathrm{p}<0.001,{ }^{\mathrm{b}} \mathrm{p}<0.001$ vs LPS by one way ANOVA.

\section{Discussion}

LPS is ubiquitously present as a contaminant on airborne particles and local exposure to LPS results in ARDS. This laboratory [17, 20-21] has previously shown that endotoxin exposure with a
LPS in rats causes a reproducible pattern of ARDS. This was associated with surfactant dysfunction and a reduction in surfactant protein (SP) A levels in the surfactant of the injured animals [17]. In this study, we detected apoptotic hallmarks, such as DNA fragmentation, 
expression of cytoplasmic and mitochondrial proteins along with activation of caspases following LPS exposure which is blocked by surfactant instillation derived from the natural as well as synthetic source.

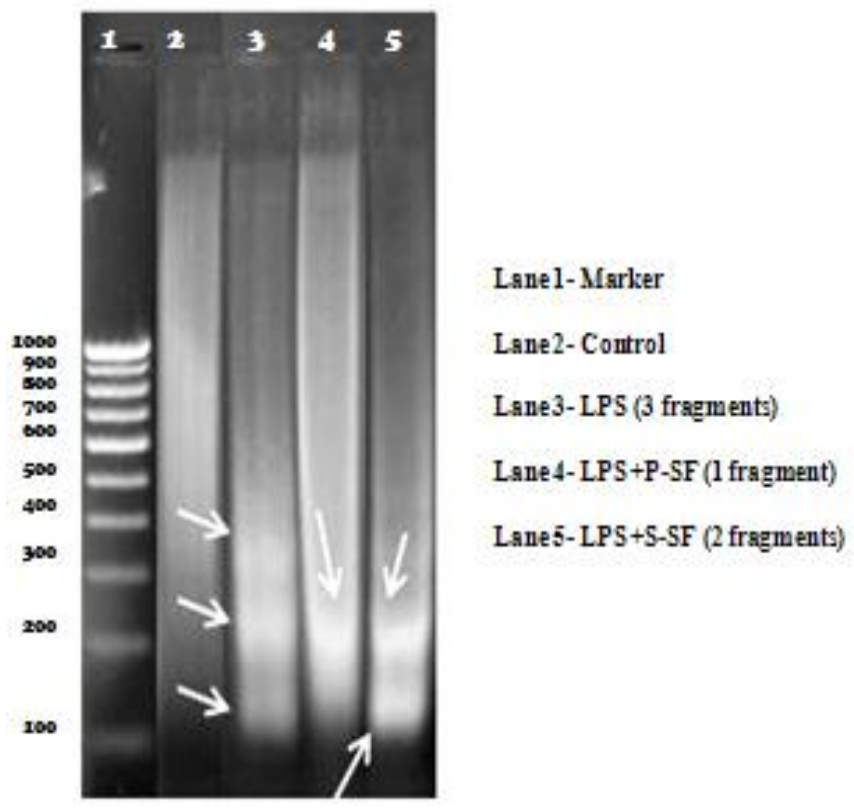

Figure 4- Photomicrograph shows the fragmentation of DNA from each group. LPS leads to increased DNA laddering as compared to the LPS + surfactant and control group.

Recently the sensitivity of tissues to apoptosis, has been closely linked to the intracellular concentrations of cell-death regulators, which include Bcl-2 and Bax. High levels of Bcl-2 prevent mitochondrial dysfunction and protect against apoptosis, whereas high levels of Bax promote apoptosis [22]. To analyze the relationship between surfactant and LPS-mediated apoptotic cascade, we investigated mitochondrial translocation of Bax and cytochrome $c$ release in cytosol through Western blot analysis and immunohistochemistry. After treatment with LPS a significantly increased expression of Bax was observed in the mitochondrial fraction, pointing to its increased translocation to the mitochondria. Surfactant treatment decreased the translocation of Bax to the mitochondria as visible by the decrease in protein expression of this protein. Cytochrome $c$ however, showed a low retention in mitochondria after LPS treatment as very high expression was observed in the cytosolic fraction. The observations implicate that increased mitochondrial translocation of Bax is mediating the LPS derived apoptosis. It can be further suggested that surfactant mediated decreased Bax expression may prevent the release of apoptotic factor, cytochrome $c$.

Molecular interactions between pro- and antiapoptotic Bcl-2 family members are known to regulate apoptosis at the level of the mitochondrial membrane. Bcl-2 antagonizes the activities of Bax and Bak, thus inhibiting apoptosis. Bax and Bak promote mitochondrial membrane disruption and the release of factors from the mitochondria that activate caspases, resulting in apoptosis. We have shown that the anti-apoptotic activity of Bcl-2 was higher after surfactant treatment along with LPS and decreased translocation of Bax to the mitochondria. Our findings of marked expression of Bax suggest that LPS-associated apoptosis in ARDS may be facilitated by the induction of Bax. In pigs, the endotoxic shock-mediated liver and spleen cell apoptosis was associated with a decrease in Bcl-2 expression [23]. Hotchkiss and colleagues [24] had also showed that overexpression of $\mathrm{Bcl}-2$ in transgenic mice decreases apoptosis and improve survival in a sepsis model. It is also known that Bcl-2 prevents apoptotic mitochondrial dysfunction by regulating proton flux [25] or mitochondrial transition pore permeability [26].

In animal models, ARDS is associated with neutrophils influx which is responsible for the generation of free radicals, release of toxic contents which induce apoptosis, presumably through damage to DNA [27], demonstrating that infiltrating neutrophils contribute to increased DNA laddering which is seen in lungs after LPS exposure. Korsmeyer et al [28] postulated that free radical induced apoptosis is regulated by the intracellular levels of Bcl-2 and Bax. In this regard, both Bcl-2 and Bax have been localized to mitochondria, nuclear membranes, and the endoplasmic reticulum, which are sites where free radicals are generated.

\section{Conclusion}

In conclusion, mitochondrial dysfunction commonly occurs in LPS mediated ARDS and is 
associated with subsequent release of mitochondrial intermembrane proteins into the cytosol, suggesting damage to the mitochondria and activation of endogenous cysteine proteases. Therapeutic surfactant interventions may have significant anti-inflammatory and anti-apoptotic effects and open new possibilities to the diagnosis and treatment of severe ARDS.

\section{Acknowledgement}

This work is supported by grant from Indian Council of Medical Research (ICMR), New Delhi (Ref. No. 61/5/2005-BMS).

\section{Declaration of interest}

The authors report no conflicts of interest. The authors alone are responsible for the content and writing of the paper.

\section{References}

1. Piantadosi, C.A.; Schwartz, D.A. The acute respiratory distress syndrome. Ann Intern Med, 2004, 141, 460-470.

2. Abraham, E. Neutrophils and acute lung injury. Crit.Care Med, 2003, 31, S195-S199. DOI: 10. 1097/01.CCM0000057843.47705.E8

3. Matute-Bello, G.; Martin, T.R. Science review: apoptosis in acute lung injury. Crit Care, 2003, 7, 355-358. DOI: 10.1186/cc1861

4. Lewis, J.F.; Hobe, A.H. Surfactant and the adult respiratory distress syndrome. Am Rev Respir Dis, 1993, 147, 218-233.

5. Gregory, T.; Longmore, W.J.; Moxley, M.A.; Whitsett, J.A. Surfactant chemical composition and the biophysical activity in the acute respiratory distress syndrome. J Clin Invest, $\quad 1991, \quad 88, \quad$ 1976-1981. DOI:10.1172/JCI115523

6. Lewis, J.F.; Ikegami, M.; Jobe, A.H. Altered surfactant function and metabolism in rabbits with acute lung injury. J Appl Physiol, 1990, 69, 2303-2310.

7. Hotchkiss, R.S.; Swanson, P.E.; Freeman, B.D.; Tinsley, K.W.; Cobb, J.P.; Matuschak, G.M.; Buchman, T.G.; Karl, I.E. Apoptotic cell death in patients with sepsis, shock, and multiple organ dysfunction. Crit Care Med, 1999, 27, 1230-1251.

8. Kawasaki, M.; Kuwano, K.; Hagimoto, N.; Matsuba, T.; Kunitake, R.; Tanaka, T.; Maeyama, T.; Hara, N. Protection from lethal apoptosis in lipopolysaccharide-induced acute lung injury in mice by a caspase inhibitor. $A m$ $J \quad P a t h o l, \quad 2000, \quad 157, \quad 597-603$. DOI:10.1016/S0002-9440(10)64570-1

9. Rudkowski, J.C.; Barreiro, E.; Harfouche, R.; Goldberg, P.; Kishta, O.; D’Orleans-Juste, P.; Labonte, J.; Lesur, O.; Hussain, S.N. Roles of iNOS and nNOS in sepsis-induced pulmonary apoptosis. Am J Physiol Lung Cell Mol Physiol, 2004, 286, L793-L800. DOI: 10.1152/ ajplung.00266.2003

10. Nagata, S. Apoptosis by death factor. Cell, 1997, 88, 355-365. DOI. Org/10.1016/S00928674(00)81874-7

11. Degterev, A.; Boyce, M.; Yuan, J. A decade of caspases. Oncogene, 2003, 22, 8543-8567. DOI:10.1038/sj.onc.1207107

12. Takahashi, A. Caspase: executioner and undertaker of apoptosis. Int J Hematol, 1999, 70, 226-232.

13. Murphy, B.M.; O’Neill, A.J.; Adrain, C.; Watson, R.W.; Martin, S.J. The apoptosome pathway to caspase activation in primary human neutrophils exhibits dramatically reduced requirements for cytochrome c. $J$ Exp Med, 2003, 197, 625-632. DOI: $10.1084 /$ jem.20021862

14. Fossati, G.; Moulding, D.A.; Spiller, D.G.; Moots, R.J.; White, M.R.; Edwards, S.W. The mitochondrial network of human neutrophils: role in chemotaxis, phagocytosis, respiratory burst activation, and commitment to apoptosis. J Immunol, 2003, 170, 1964-1972.

15. Simon, H.U.; Haj-Yehia, A.; Levi-Schaffer, F. Role of reactive oxygen species (ROS) in apoptosis induction. Apoptosis, 2000, 5, 415418. DOI: 10.1023/A:1009616228304

16. Maianski, N.A.; Roos, D.; Kuijpers, T.W. Tumor necrosis factor $\alpha$ induces a caspaseindependent death pathway in human neutrophils. Blood, 2003, 101, 1987-1995. DOI: 10.1182/blood-2002-02-0522 
17. Mittal, N.; Sanyal, S.N. Exogenous surfactant suppresses inflammation in experimental endotoxin-induced lung injury. $J$ Enviorn Toxicol Pathol Oncol, 2009, 28, 341-349.

18. Mittal, N.; Sanyal, S.N. Immunomodulatory properties of exogenous surfactant in adult rat alveolar macrophages. Immunopharm Immunot, 2010, 32, 153-159. DOI:10.3109/08923970903225119

19. Bradford, M.M. A rapid and sensitive method for the quantitation of microgram quantities of protein utilizing the principle of protein-dye binding. Anal Biochem, 1976, 72, 248-254.

20. Mittal, N.; Sanyal, S.N. Cyclooxygenase inhibition enhances the effects of surfactant therapy in endotoxin induced rat model of ARDS. Inflamm, 2010, 34(2), 92-98 DOI: 10.1007/s10753-010-9211-6

21. Mittal, N.; Sanyal, S.N. Intratracheal Instillation of Surfactant Inhibits Lipopolysaccharide-induced Acute Respiratory Distress Syndrome in Rats. Am J Biomed Sci, 2010, 2, 190-201.

22. Shimizu, S.; Egushi, Y.; Kamike, W.; Funahashi, Y.; Mignon, A.; Lacronique, V.; Matsuda, H.; Tsujimoto, Y. Bcl-2 prevents apoptotic mitochondrial dysfunction by regulating proton flux, Proc Natl Acad Sci USA, 1998, 95, 1455-1459.

23. Haendeler, J.; Messmer, U.K.; Brüne, B.; Neugebauer, E.; Dimmeler, S. Endotoxic shock leads apoptosis in vivo and reduces Bcl-2, Shock, 1996, 6, 405-409.

24. Hotchkiss, R.S.; Swanson, P.E.; Knudson, C.M.; Chang, K.C.; Cobb, J.P.; Osborne, D.F.; Zollner, K.M.; Buchman, T.G.; Korsmeyer, S.J.; Karl, I.E. Overexpression of Bcl-2 in transgenic mice decreases apoptosis and improves survival in sepsis, J Immunol, 1999, $162,4148-4156$.

25. Kroemer, G. The proto-oncogene Bcl-2 and its role in regulating apoptosis, Nat Med, 1997, 3, 614-620. DOI:10.1038/nm0697-614

26. Shimizu, S.; Naritam, M.; Tsujimoto, Y. Bcl-2 family proteins regulate the release of apoptogenic cytochrome c by the mitochondrial channel VDAC, Nature, 1999, 399, 483-487. DOI:10.1038/20959

27. Korsmeyer, S.J.; Yin, X.M.; Oltvai, Z.N.; Veis Novack, D.J.; Linette, G.P. Reactive oxygen species and the regulation of cell death by the Bcl-2 gene family, Biochim Biophys Acta, 1995, 1271, 63-66.

28. Korsmeyer, S.J.; Shutter, J.R.; Veis, D.J.; Merry, D.E.; Oltvai, Z.N. Bcl-2/Bax: a rheostat that regulates an anti-oxidant pathway and cell death, Semin Cancer Biol, 1993, 4, 327-332. 